\title{
Less is more in nutrition: critically ill patients are starving but not hungry
}

\author{
Yaseen M. Arabi ${ }^{1 *}$ (D) Annika Reintam Blaser ${ }^{2,3}$ and Jean-Charles Preiser ${ }^{4}$
}

(0) 2019 Springer-Verlag GmbH Germany, part of Springer Nature

\section{The critically ill: metabolically strained, but anorexic}

Critical illness is associated with a metabolic response that is considered as adaptive and is mediated by increase in sympathetic nervous system activity and release of pituitary hormones and inflammatory mediators [1]. At the same time, resistance to anabolic agents develops and the pathways for energy production are modified to facilitate the use of alternative substrates [1]. While these mechanisms are triggered to increase the availability of energy substrates, they lead to substantial catabolic state and loss of muscle mass.

Despite the described metabolic pattern, anorexia is a common feature of critical illness. Anorexia is induced through several signaling pathways that include increased pro-inflammatory cytokines (such as interleukin- $1 \beta$ and tumor necrosis factor- $\alpha$ ), increased leptin secretion from the adipose tissue (satiety hormone), and reduced ghrelin secretion from stomach (hunger hormone) [2-4]. It has been suggested that anorexia is an adaptive component of the host response, although the exact role is largely unclear [5].

\section{Nutritional support \\ Amount matters?}

The benefit of early enteral nutrition (EN) could be mostly related to its trophic effect on gut mucosa [6]. This may explain the finding that early EN compared to late EN is associated with reduced mortality in unselected ICU patients [7]. In addition, early nutritional support

\footnotetext{
*Correspondence: arabi@ngha.med.sa

${ }^{1}$ Intensive Care Department, King Abdullah International Medical Research Center (KAIMRC), College of Medicine, King Saud Bin Abdulaziz University for Health Sciences (KSAU-HS), P.O. Box 22490, Riyadh 11426 , Kingdom of Saudi Arabia

Full author information is available at the end of the article
}

has been advocated with the premise of mitigating the catabolic status associated with critical illness.

On the other hand, studies in animals with bacterial sepsis suggest that anorexia may be protective and that provision of nutrients to cover full energy expenditure may be detrimental. Mice infected with $L$. monocytogenes had a dose-dependent decrease in food intake and had higher mortality when given enteral supplementation by force of 1 kilocalorie twice daily (equivalent of onefifth of healthy mouse daily food intake) [8]. This may be mediated through upregulation of autophagy, which plays a critical role in clearing pathogens and in removal of damaged proteins and organelles [5].

In critically ill humans and in contrast to former observational findings, several randomized controlled trials showed that EN targeting energy expenditure in the early phase of critical illness did not improve survival or any other clinical outcome compared to trophic feeding or permissive underfeeding [9-12]. In contrast, higher energy intake resulted in increased insulin requirements and gastrointestinal complications and possibly infections [9-12]. Taken together, current data argue for a progressive and stepwise increase of nutrition [13] (Fig. 1).

\section{Timing matters?}

Two clinical trials in critically ill adults and children demonstrated that early supplemental parenteral nutrition (PN) compared to PN delayed by 1 week was associated with delayed recovery, decreased likelihood of live discharge from the ICU, and increased renal and infectious complications $[14,15]$. One explanation is that early full PN might suppress autophagy in the early phase of illness, when it is most needed. Another explanation is that during the acute phase, endogenous energy production is high and cannot be suppressed by exogenous energy provision, and thereby providing full calories exogenously 


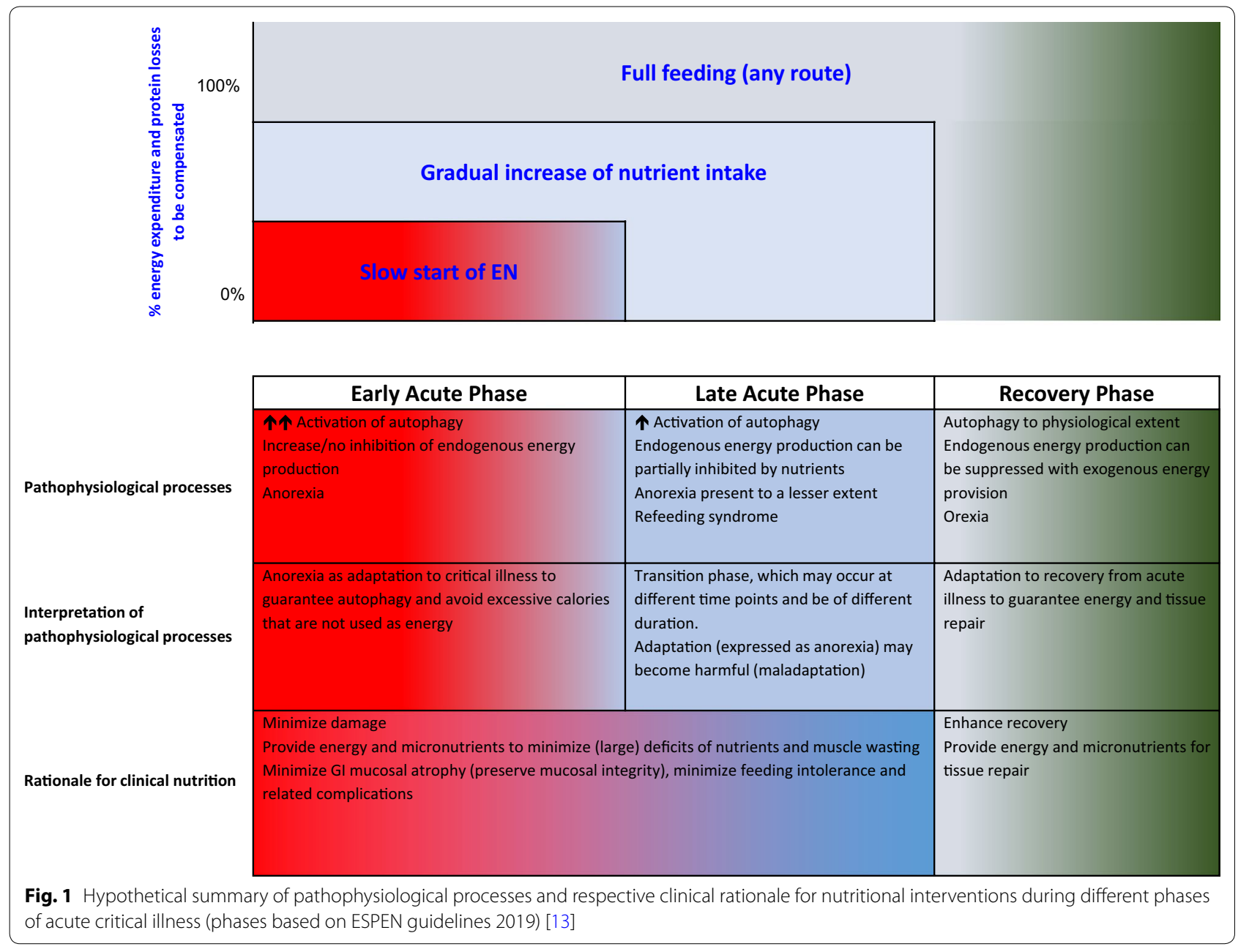

leads to overfeeding with its negative effects [1]. On the other hand, augmenting nutritional support after that phase may help in recovery by supplementing macronutrients that are needed for tissue repair. Unfortunately, there is no marker at present that signals the transition point from catabolic to anabolic phase of critical illness, which is likely to vary among patients.

However, without modern critical care, most of the ICU patients would not survive; therefore adaptation mechanisms may turn into maladaptation and probably should not just be observed for prolonged time, e.g., prolonged full starvation in patients with prolonged hemodynamic instability is unlikely to be beneficial. Results of available studies need to be interpreted with caution considering non-nutritional energy provision (dextrose and propofol). Nevertheless, the issue of timing may explain conflicting results regarding the route and amount, suggesting that timing and amount should always be interpreted together as a composition [16]. Additionally, data on the optimal amount of protein during the acute and recovery phases are limited and several RCTs are ongoing at present.

\section{Type of patient matters?}

Another aspect is related to the heterogeneity of critically ill patient population, in terms of nutritional status, gastrointestinal function, hemodynamic status, and the nature of illness. Based on observational data, nutritional assessment tools, such as the Nutrition Risk in Critically ill (NUTRIC) score, have been suggested to identify critically ill patients most likely to benefit from aggressive nutrition therapy [17]. However, post hoc analysis of data from the PermiT trial (The Permissive Underfeeding versus Target Enteral Feeding in Adult Critically Ill Patients trial) showed that the NUTRIC score could not differentiate who might benefit or be harmed from permissive underfeeding or standard feeding [18]. In patients with refeeding syndrome (hypophosphatemia within $72 \mathrm{~h}$ of initiation of nutrition), restricted versus standard caloric intake resulted in no difference in the primary endpoint 
of the number of days alive after ICU discharge, but with more patients alive at day 60 [19]. Among patients on vasopressors, $\mathrm{PN}$ or EN-targeting normocaloric goals within $24 \mathrm{~h}$ after intubation did not result in a difference in the primary endpoint of 28-day mortality or ICUacquired infections, but was associated with an increase in bowel ischemia and acute colonic pseudo-obstruction [20]. Whether these results can be extrapolated also to other subpopulations of critically ill and whether a lowdose early feeding with gradual increase would make a change in such comparison of EN vs PN remain to be clarified. Taken together, no patient groups for any specific nutritional intervention can currently be distinguished based of phenotypes, whereas benefit of early full nutrition has not been proven in any subgroup.

In conclusion, in the early acute phase of critical illness, harm from both full starvation and overfeeding should be minimized, whereas full nutrition can enhance recovery only after transition into anabolic phase. To detect such transition in metabolism and modify clinical nutrition to support adaptation, but at the same time, fight maladaptation during prolonged acute phase remains major challenge. Current data support early EN (within 24-48 h), if no contraindication, started at low dose and increased gradually. During the recovery phase, increased protein and energy should be provided to support anabolic repair processes.

\footnotetext{
Author details

${ }^{1}$ Intensive Care Department, King Abdullah International Medical Research Center (KAIMRC), College of Medicine, King Saud Bin Abdulaziz University for Health Sciences (KSAU-HS), P.O. Box 22490, Riyadh 11426, Kingdom of Saudi Arabia. ${ }^{2}$ Department of Intensive Care Medicine, Lucerne Cantonal Hospital, Lucerne, Switzerland. ${ }^{3}$ Department of Anaesthesiology and Intensive Care, University of Tartu, Tartu, Estonia. ${ }^{4}$ Department of Intensive Care, Erasme University Hospital, Université Libre de Bruxelles, Brussels, Belgium.

\section{Compliance with ethical standards}

\section{Conflicts of interest}

Dr. Yaseen Arabi's institution received funding from King Abdullah International Medical Research Center, Riyadh, Saudi Arabia, and King Abdulaziz City for Science and Technology, Riyadh, Saudi Arabia for the studies on permissive underfeeding and for biomarker substudies. Dr. Annika Reintam Blaser received speaker fees from Fresenius and Nestlé and a study grant from Fresenius given to University of Tartu. Dr. Jean-Charles Preiser received speaker fees from Baxter, Fresenius, Nestle and Nutricia.
}

\section{Publisher's Note}

Springer Nature remains neutral with regard to jurisdictional claims in published maps and institutional affiliations.

Received: 4 August 2019 Accepted: 21 August 2019
Published online: 17 September 2019

References

1. Preiser JC, Ichai C, Orban JC, Groeneveld AB (2014) Metabolic response to the stress of critical illness. Br J Anaesth 113(6):945-954

2. Langhans W (2007) Signals generating anorexia during acute illness. Proc Nutr Soc 66(3):321-330

3. Tzanela M, Orfanos S, Tsirantonaki M et al (2006) Leptin alterations in the course of sepsis in humans. In Vivo 20(4):565-570

4. Nematy M, O'Flynn JE, Wandrag L et al (2006) Changes in appetite related gut hormones in intensive care unit patients: a pilot cohort study. Crit Care 10(1):R10

5. van Niekerk G, Isaacs AW, Nell T, Engelbrecht AM (2016) Sickness-associated anorexia: mother nature's idea of immunonutrition? Mediat Inflamm 2016:8071539

6. McClave SA, Lowen CC, Martindale RG (2018) The 2016 ESPEN Arvid Wretlind lecture: the gut in stress. Clin Nutr 37(1):19-36

7. Tian F, Heighes PT, Allingstrup MJ, Doig GS (2018) Early enteral nutrition provided within 24 hours of ICU admission: a meta-analysis of randomized controlled trials. Crit Care Med 46(7):1049-1056

8. Wang A, Huen SC, Luan HH et al (2016) Opposing effects of fasting metabolism on tissue tolerance in bacterial and viral inflammation. Cell 166(6):1512-1525

9. National Heart L, Blood Institute Acute Respiratory Distress S, Rice TW et al (2012) Initial trophic vs full enteral feeding in patients with acute lung injury: the EDEN randomized trial. JAMA 307(8):795-803

10. Arabi YM, Aldawood AS, Haddad SH et al (2015) Permissive underfeeding or standard enteral feeding in critically ill adults. N Engl J Med 372(25):2398-2408

11. Al-Dorzi HM, Albarrak A, Ferwana M, Murad MH, Arabi YM (2016) Lower versus higher dose of enteral caloric intake in adult critically ill patients: a systematic review and meta-analysis. Crit Care 20(1):358

12. Target Investigators ftACTG, Chapman M, Peake SL et al (2018) Energydense versus routine enteral nutrition in the critically ill. N Engl J Med 379(19):1823-1834

13. Singer $P$, Blaser AR, Berger MM et al (2019) ESPEN guideline on clinical nutrition in the intensive care unit. Clin Nutr 38(1):48-79

14. Casaer MP, Mesotten D, Hermans G et al (2011) Early versus late parenteral nutrition in critically ill adults. N Engl J Med 365(6):506-517

15. Fivez T, Kerklaan D, Mesotten D et al (2016) Early versus late parenteral nutrition in critically ill children. N Engl J Med 374(12):1111-1122

16. Elke G, van Zanten AR, Lemieux M et al (2016) Enteral versus parenteral nutrition in critically ill patients: an updated systematic review and metaanalysis of randomized controlled trials. Crit Care 20(1):117

17. Heyland DK, Dhaliwal R, Jiang X, Day AG (2011) Identifying critically ill patients who benefit the most from nutrition therapy: the development and initial validation of a novel risk assessment tool. Crit Care 15(6):R268

18. Arabi YM, Aldawood AS, Al-Dorzi HM et al (2017) Permissive underfeeding or standard enteral feeding in high and low nutritional risk critically ill adults: post-hoc analysis of the PermiT trial. Am J Respir Crit Care Med 195:652-662

19. Doig GS, Simpson F, Heighes PT et al (2015) Restricted versus continued standard caloric intake during the management of refeeding syndrome in critically ill adults: a randomised, parallel-group, multicentre, singleblind controlled trial. Lancet Respir Med 3(12):943-952

20. Reignier J, Boisrame-Helms J, Brisard L et al (2018) Enteral versus parenteral early nutrition in ventilated adults with shock: a randomised, controlled, multicentre, open-label, parallel-group study (NUTRIREA-2). Lancet 391(10116):133-143 